\title{
Final DOE Progress Report
}

\section{Randy L. Jirtle, Ph.D.}

\section{Duke University Medical Center}

The overall hypothesis of this grant application is that low dose ionizing radiation (LDIR) elicits adaptive responses in part by causing heritable DNA methylation changes in the epigenome. This novel postulate was tested by determining if the level of DNA methylation at the Agouti viable yellow $\left(A^{v y}\right)$ metastable locus is altered, in a dose-dependent manner, by low dose radiation exposure ( $<10 \mathrm{cGy}$ ) during early gestation. This information is particularly important to ascertain given the increased use of CT scans in disease diagnosis, increased number of people predicted to live and work in space, and the present concern about radiological terrorism.

We showed for the first time that LDIR significantly increased DNA methylation at the $A^{v y}$ locus in a sex-specific manner $(p=0.004)$. Average DNA methylation was significantly increased in male offspring exposed to doses between $0.7 \mathrm{cGy}$ and $7.6 \mathrm{cGy}$ with maximum effects at $1.4 \mathrm{cGy}$ and $3.0 \mathrm{cGy}(\mathrm{p}<0.01)$. Offspring coat color was concomitantly shifted towards pseudoagouti $(p<0.01)$. Maternal dietary antioxidant supplementation mitigated both the DNA methylation changes and coat color shift in the irradiated offspring $(p<0.05)$. Thus, LDIR exposure during gestation elicits epigenetic alterations that lead to positive adaptive phenotypic changes that are negated with antioxidants, indicating they are mediated in part by oxidative stress. These findings provide evidence that in the isogenic $A^{v y}$ mouse model epigenetic alterations resulting from LDIR play a role in radiation hormesis, bringing into question the assumption that every dose of radiation is harmful.

Our findings not only have significant implications concerning the mechanism of hormesis, but they also emphasize the potential importance of this phenomenon in determining human risk at low radiation doses. Since the epigenetic regulation of genes varies markedly between species, the effect of LDIR on other epigenetically labile genes (e.g. imprinted genes) in animals and humans needs to be defined. 


\section{Publications:}

1. Dolinoy, D.C., Weidman, J.R., and Jirtle, R.L. Epigenetic gene regulation: Linking early developmental environment to adult disease. Reprod. Toxicol. 23: 297-307, 2007.

2. Jirtle, R.L., and Skinner, M.K. Environmental epigenomics and disease susceptibility. Nat. Rev. Genet. 8: 253-562, 2007.

3. Dolinoy, D.C., Das, R., and Jirtle, R.L. Epigenetics, the fetal environment, and the Agouti gene. Pediatric Res. 61: 30R-37R, 2007.

4. Weidman, J.R., Dolinoy, D.C., Murphy, S.K., and Jirtle, R.L. Cancer susceptibility: epigenetic manifestation of environmental exposures. Cancer J. 13: 9-16, 2007.

5. Dolinoy D.C., Huang, D., and Jirtle, R.L. Maternal nutrient supplementation counteracts bisphenol A-induced DNA hypomethylation in early development. Proc. Natl. Acad. Sci. USA 104: 13056-13061, 2007.

6. Luedi, P.P., Dietrich, F.S., Weidman, J.R., Bosko, J.M., Jirtle RL, and Hartemink, A.J. Computational and experimental identification of novel human imprinted genes. Genome Res. 17: 1723-1730, 2007.

7. Dolinoy, D.C., and Jirtle, R.L. Environmental epigenomics in human health and disease. Environ. Mol. Mutagen 9: 4-8. 2008.

8. Jirtle, R.L. Epigenome: The program for human health and disease. Epigenomics 1: 13-16, 2009.

9. Das, R., Hampton, D.D., and Jirtle, R.L. Imprinting evolution and human health. Mamm. Genome 20: 563-572, 2009.

10. Bernal, A.J., and Jirtle, R.L. Epigenomic disruption: The effects of early developmental exposures. Birth Defects Res. A Clin. Mol. Teratol. 88: 938-944, 2010.

11. Das Chakraborty, R., Bernal ,A.J., Schoch, K., Howard, T.D., Ip, E.H., Hooper, S.R., Keshavan, M.S., Jirtle, R.L., and Shashi, V. Dysregulation of DGCR6 and DGCR6L: psychopathological outcomes in chromosome 22q11.2 deletion syndrome. Transl. Psychiatry 2: e105, 2012.

12. Bernal, A.J., Dolinoy, D.C., Huang, D., Skaar, D.A., Weinhouse, C., and Jirtle, R.L. Adaptive Radiation-induced Epigenetic Alterations Mitigated by Antioxidants. FASEB J 27: 665-671, 2013.

13. Skaar, D.A., Li, Y., Bernal, A.J., Hoyo, C., Murphy, S.K., and Jirtle, R.L. The Human Imprintome: Regulatory Mechanisms, Methods of Ascertainment, and Roles in Disease Susceptibility. ILAR J 53: (in press), 2013. 